\title{
Chapter 16 \\ Considering Religion and Tradition in Climate Smart Agriculture: Insights from Namibia
}

\author{
Julia Davies, Dian Spear, Angela Chappel, Nivedita Joshi, Cecile Togarepi, \\ and Irene Kunamwene
}

\subsection{Introduction}

Rural communities in the semi-arid areas of southern Africa are particularly vulnerable to climate change because they depend predominantly on rain-fed agriculture to support their livelihoods. In addition, a number of non-climatic issues-including poverty, inequality, education deficits and poor governance-render communities in these areas even more susceptible to climate-related problems. Climate-smart agriculture (CSA) has the potential to increase the resilience of these vulnerable communities because it integrates environmental management and climate-change adaptation with social and economic sustainability (Chioreso and Munyayi 2015).

The implementation of CSA, however, has proven difficult in southern Africa. Previous studies have shown that key barriers include inadequate policy and insufficient access to finances, technology, land and human resources (Barnard et al. 2015; Sibanda et al. 2017; Williams et al. 2015). Less is understood, however, about how cultural barriers-norms, values, historical legacies, religious and traditional beliefs and social identities_affect the adoption of CSA (Thomalla et al. 2015). This study considers the role played by devotion (religious faith and belief) and respect for tradition (preservation of time-honoured customs) (Schwartz 1992) in

J. Davies $(\bowtie) \cdot D$. Spear · I. Kunamwene

African Climate and Development Initiative (ACDI), University of Cape Town,

Rondebosch, South Africa

e-mail: julia.davies@uct.ac.za
A. Chappel · N. Joshi
Environmental and Geographical Sciences, University of Cape Town,
Cape Town, South Africa
C. Togarepi
Department of Agricultural Economics and Extension, Old Administration Block,
University of Namibia Ogongo Campus, Ogongo, Namibia 
CSA adoption in Namibia. Research involved a review of existing literature and the collection of empirical data through 60 semi-structured interviews. These interviews were conducted with farmers in the semi-arid north-central region ${ }^{1}$ of Namibia in July 2017 as part of the Adaptation at Scale in Semi-Arid Regions (ASSAR) ${ }^{2}$ research project.

The agricultural sector contributes to only $3.7 \%$ of the country's gross domestic product, but small-scale and subsistence crop and livestock farming remains an important aspect of livelihood security in rural areas, where more than half of the national population resides (MAWF 2015). Farming, moreover, is fundamental to the cultural identity of Namibian people, particularly in the Oshiwambo culture. Increasing the resilience of Namibia's agricultural sector is thus key not only for alleviating poverty and food insecurity but also for preserving local socio-cultural identities.

In recent years the government of Namibia has developed policies and plans to enhance agricultural growth, improve natural resource management and upscale climate-change interventions. ${ }^{3}$ In 2015 a draft national CSA programme was adopted (MET 2015). Farmers, with support from the government, non-governmental organisations and national research institutions, have begun implementing CSA practices. These include initiatives such as drip irrigation, planting early-maturing mahangu (pearl millet), engaging in small-scale rice farming, using draught-animal power and farm tools (instead of tractors) for ripping fields, and selecting more hardy, drought-tolerant cattle breeds.

Some farmers, however, have been slow to adopt such approaches. Our study found that cultural factors-especially religious belief, reliance on traditional knowledge and the symbolic significance of certain agricultural practices-have played a role in the low uptake of CSA in Namibia. We argue, however, that these barriers can be turned into opportunities: By working with rather than against religious and traditional value systems, extension workers could promote the adoption of CSA and thereby help to reduce the impacts of climate change and variability. These benefits could be achieved through one or more of the following avenues: (i) positioning religious and traditional leaders as climate change champions; (ii) integrating scientific information with traditional knowledge; and (iii) framing CSA in such a way that it complements rather than conflicts with religious beliefs or traditional practices.

\footnotetext{
${ }^{1}$ Interviews were conducted in the Onesi Constituency, which falls within the Omusati Region. The specific study sites were the Okathitukeengombe, Oshihau and Omaenene villages.

${ }^{2}$ The ASSAR project (2014-2018) aims to deepen the understanding of climate vulnerability and adaptation in semi-arid regions of Africa and Asia, where millions of people are highly vulnerable to climate-related impacts and risks. See http://www.assar.uct.ac.za/

${ }^{3}$ Some key policies relevant for CSA implementation and scale-out in Namibia include: Namibia Vision 2030; National Development Plan 4 (2012/13-2016/17); National Agricultural Policy (2015); National Disaster Risk Management Policy (2009); National Drought Policy and Strategy (1997) and National Climate Change Policy (2011) (as cited in MET 2015).
} 


\subsection{Cultural Barriers to CSA Adoption}

\subsubsection{Religious Faith and Belief}

Religious faith has proved a hindrance to the embrace of scientific climate forecasts. In Namibia, seasonal climate forecasts (SCFs) are produced by the national meteorological services and then disseminated to farmers via agricultural extension officers and radio broadcasts, the latter of which reach $90 \%$ of the population. In addition, a new online platform (http://www.lisa.com.na) allows farmers to interact with experts via text message. Some farmers in northern Namibia, however, do not take advantage of this information. Reasons for the low levels of uptake of SCF by farmers in Africa include problems of downscaling, a limited capacity among farmers to understand forecast data, and mismatches between the information provided by SCF and what is perceived as useful on the ground (Luseno et al. 2016; Singh et al. 2017; Ziervogel and Calder 2003; Ziervogel and Opere 2010). Another major reason, however, is the Christian belief, prevalent in northern Namibia, that rainfall and crop productivity cannot be predicted but are solely dependent on the will of God (also see Angula et al. 2016; Selato 2017; Spear et al. 2015). As explained by an interview respondent, "I cannot tell if the drought is going to worsen or not-that is God's work" (Farmer 1). Another explained that "only God knows what is in the future" (Farmer 2). Strong religious beliefs can make people accept their circumstances rather than use forecasts to inform their practices. From this perspective, any anomalies in climate are perceived as punishment for people displeasing God in some way: "maybe God is angry because of the things people are doing-that is why we are not getting enough rainfall" (Farmer 3).

\subsubsection{Symbolic Significance of Agricultural Practice}

While livestock rearing contributes to livelihood security for farmers in southern Africa in non-drought times, it can increase farmers' vulnerability during extended periods of low rainfall. Overstocking places more pressure on food and water resources and may cause increased land degradation. Drought can also cause animals to die, a major financial loss for farmers. One farmer explained, "we used to use animals to plough the field but those animals died in the drought last year and the year before" (Farmer 10).

But even farmers who have previously experienced losses still choose to keep livestock in the face of drought. The reasons for this reluctance are many: low market prices, collapse of markets, a lack of access to markets and a poor understanding of the reasons to sell (Speranza 2010; Togarepi et al. 2016). In some cases, however, a failure to sell is linked to the symbolic significance of livestock (Doran et al. 1979; Hegga et al. 2016; Stroebel et al. 2008). In Namibia, cattle are often perceived as a direct measure of affluence, status, prestige and security. Livestock rearing is used 
as an informal insurance system, and some farmers see cattle as more valuable than money itself. One farmer in northern Namibia explained, "I believe that cows help to bail me out of my problems - that's why I will continue to keep them" (Farmer 6). Another said, "I believe that livestock is a part of our culture and by owning them, I am definitely better than someone who doesn't have them. If I sell my cows, I feel like I am cheating on my culture" (Farmer 7). The cultural identity of Ovambo men is closely tied to the ownership of livestock: "A man is his cattle" (Farmer 8); "My parents told me that as a man you should own livestock. One of the definitions of a man is having livestock. I fully agree with them" (Farmer 9). These strong cultural attachments make farmers reluctant to sell stock, even when forecasts call for severe drought.

\subsubsection{Traditional Agricultural Knowledge}

The lack of uptake of SCF is sometimes due to a tendency to favour traditional weather knowledge over scientific climate forecasts (Newsham and Thomas 2011; Mogotsi et al. 2011; Selato 2017; Jiri et al. 2016). In Namibia, farmers plant their crops according to traditional calendar dates (December 15-February 15) even if the SCF indicates an earlier or later onset of the rainfall season. A farmer describes her strategy: "I plough the first set of crops at the end of December ... the second set mid-January ... and the third set at the end January/beginning of February. ... It should rain by the time of the second or third ploughing session" (Farmer 4). Traditional forecasting methods are also still widely used in southern Africa. In Botswana, for example, farmers observe the flowering of trees, the position of stars and the persistence of "pregnant" clouds to determine how much rain the season is likely to bring (Mogotsi et al. 2011; Selato 2017). Similarly, a stakeholder from Namibia explained that "according to indigenous knowledge, we can predict "yes, it [drought] might worsen"' (Farmer 5). While traditional forecasting methods have indeed proven valuable, they are also becoming less accurate due to climate change (Angula et al. 2016), rendering SCF more important than ever.

Uptake of new farming technologies-including new crops or cultivars-can also be stymied by adherence to traditional norms. In northern Namibia many farmers refuse to adopt new practices even if they recognize that the climate is changing: "We haven't changed the crops that we grow. We don't change them at all even if it is dry or there is good rainfall" (Farmer 15). As with traditional forecasting methods, farmers are reluctant to change practices that have been passed down through generations: "We will keep farming the same way because in the Oshiwambo culture we don't like to change tradition" (Farmer 16). One farmer explained, "I fear new practices won't work and my yield will be even worse" (Farmer 17). In northcentral Namibia, farmers have a strong cultural attachment to mahangu. While their preferred variety of millet is generally hardy and well-adapted to the semi-arid conditions of the region, productivity has declined over the last two decades (CPP 
2012). The Namibian government has introduced more resilient seed varieties, but many farmers have rejected them because of their slightly different appearance and taste. One explained, "We will keep farming like this forever. It is tradition so it has to continue for generations. Change to what? Mahangu is our main meal, so there is no way we can change it" (Farmer 18). Some farmers are open to trying new crop varieties, but as a supplement rather than a replacement for traditional versions. Asked about adopting new crops, one respondent answered, "maybe, but we must still grow mahangu because it is part of our culture" (Farmer 16).

It is important to note that the embrace of tradition has a generational component. Farmer 3 explained, "I am not willing to use new practices because I am old and maybe I won't carry them out correctly," and farmer 2 said, "I am very old now but if I was young and energetic I would try new farming practices." Whereas older farmers are unlikely to market their livestock even in the face of drought, younger farmers often are more flexible. One man explained, 'I'm an elder and I can't stay without livestock since it is a part of my culture" (Farmer 12). But a younger farmer claimed that "the culture is there, but it will not stop me from selling my livestock" (Farmer 11).

\subsection{Working with Religious and Traditional Belief Systems to Enable Adaptation}

Although religious and traditional beliefs sometimes prevent farmers from making more adaptive decisions, we argue that these cultural factors should not be viewed simply as barriers. These belief systems-precisely because they play such an important role in agricultural decision-making — should be viewed as an opportunity through which to catalyse the dissemination of CSA. We identify three possible avenues through which to do this.

\subsubsection{Positioning Religious and Traditional Leaders as 'Champions'}

The climate change literature increasingly acknowledges the role of "champions" or "lead farmers" in encouraging adaptation (Conservation Agriculture Task Force for Zimababwe 2008; Davies and Ziervogel 2017; Roberts 2008). However, there have been fewer attempts to recruit religious or traditional elites to play this role, despite the fact that many farmers tend to have greater confidence in information that comes from such figures. In Botswana, for example, the tradition of Letsema means that farmers must wait for permission from the village chief before they begin planting or harvesting. Even if a seasonal forecast indicates an earlier onset of rainfall, farmers will wait for word from the chief (Selato 2017). In this context, it would be 
essential for the chief to champion adaptation. Chishakwe et al. (2012) found that fostering relationships of trust with traditional leaders was essential for establishing local ownership of community-based adaptation projects in the Mayuni Conservancy in Namibia. Similarly, case studies from Malawi and Zambia highlight the role of traditional leaders in building adaptive capacity in their local communities (Reid et al. 2010).

Religious leaders could play a similar role. The staunch religious nature of much of the Ovambo society means that church leaders have substantial influence upon agricultural decision-making. They therefore could play an influential role in promoting CSA. Champions may also take the form of a church organisation rather than an individual. The Southern African Faith Communities' Environment Institute (safcei.org) is a regional multi-faith network that promotes religious education and teaching about the environment and climate change. In Zimbabwe, Foundations for Farming (www.fffzimbabwe.org) uses religious narratives to promote soil and water conservation practices such as no-till, mulching and crop rotation (Kassam et al. 2014). Similarly, the Green Anglicans in Swaziland aim "to fulfil God's call to be Earthkeepers and to care for Creation" (www.greenanglicans.org). Although such programmes can be effective, it is important that the approaches they promote are relevant to the local environmental and socio-economic contexts.

\subsubsection{Integrating Traditional and Scientific Knowledge}

Western science, though vital to creating resilience to climate change, still has much to learn from traditional bodies of ecological knowledge (Berkes et al. 2000; Mazzocchi 2006). For example, while SCF can provide information about climate change on broader spatial and temporal scales, traditional forecasting methods may help to counter downscaling issues associated with climate models, as they provide information that is more locally relevant. SCF could therefore be used to complement traditional understandings of risk and enable farmers to make more informed decisions (Ambani and Percy 2014; Singh et al. 2017; Ziervogel and Opere 2010).

Such integration is difficult and requires robust engagement between communities, experts and government (Kniveton et al. 2014; Singh et al. 2017; Thomalla et al. 2015). In Namibia the system of "indigenous land units" (ILU) has been used for decades to help farmers classify local environmental conditions and thus determine how specific areas should be used (Verlinden and Dayot 2005). This system has become less viable not only because of climate change but also because increasing densities of both human and livestock populations have added greater pressure to the environment. Despite its deficiencies, "for better or for worse, the land unit system is what farmers use to make farming decisions" (Newsham and Thomas 2011). Those wishing to successfully promote CSA approaches will need to take into account traditional methods such as ILU. A key component of this is working through traditional or religious leaders, who can advise on what changes may be practical and acceptable in the local context. 


\subsubsection{Changing the Framing of CSA}

Corner et al. (2014) highlight how, in countries such as Uganda, climate change is increasingly being communicated in ways that resonate with religious or indigenous values and beliefs. In Namibia such an approach could be particularly important when working with indigenous San communities, whose cultural identities continue to be linked strongly to the semi-nomadic, hunter-gatherer lifestyles of their ancestors. Targeted attempts by government to promote farming among the San have had limited success (Dieckmann et al. 2014). As a result, the San are today the most marginalized population group in Namibia, and many have become increasingly dependent on government aid and piecework. If adaptation projects are not designed and implemented in ways that consider their cultural traditions and beliefs, then the San are likely to become increasingly vulnerable to climate change (Dieckmann et al. 2013).

Framing information in ways that honor traditional beliefs can improve the uptake of CSA approaches. In Namibia, for example, livestock plays an important role in wedding ceremonies, funerals, communal feasts and other social and cultural events (Ziervogel 2016). Increased livestock mortality because of drought limits people's capacity to engage in such crucial activities. As a result, advice to sell livestock before a predicted drought could be framed not only as a sound financial and ecological decision but also as a way to preserve a farmer's ability to participate in traditional culture. New practices must be promoted in ways that appeal to the cultural vulnerability of communities, because "people can take extraordinary measures to protect that which they view as sacred" (Sachdeva 2016). In addition, motivating agricultural adaptation by promoting the economic benefits of CSA might prove useful among poor farming communities. Evidence from Kenya has shown that farmers who use traditional forecasting methods in conjunction with SCF see greater returns than those who use only traditional methods (Ambani and Percy 2014). Working with these value systems could enable farmers to take up practices that are more forward-looking, even if they are not sold to farmers as such.

\subsection{Implications for Development}

The values and belief systems of local communities have played a significant role in the uptake of CSA in southern Africa. In Namibia, it is clear that religion and tradition have prevented some farmers from taking steps to become more climate resilient. We argue, however, that it is important to work with religious and traditional value systems. Because these systems play such a pivotal role in agricultural decision-making, they provide a key opportunity through which to promote the dissemination and uptake of climate change information in general and CSA in particular. 
Mobilizing these approaches, however, will be difficult. Future research should consider empirically testing the application of the three avenues-positioning traditional leaders as agricultural champions, integrating traditional and scientific knowledge, and reframing CSA — suggested here. For example, it may be important for researchers to consider why, to date, there has been limited evidence of efforts to promote collaboration between agricultural extension services and religious or traditional leaders. Or, in cases where religious groups do promote CSA, studies could perhaps determine the degree to which this is done in conjunction with sound technical advice and appropriate technologies that are readily available to the congregation. In addition, future research agendas might benefit from testing novel extension approaches in neighbouring districts, revising the type of training provided to extension workers or, in cases where extension services are inaccessible, consider how individual "lead" farmers within a community may be trained in adaptation techniques and encouraged to disseminate these innovations to the broader community.

In carrying out such studies, it is essential to emphasize that there is no single solution, and future research should therefore promote flexibility and an awareness of local cultural, environmental and socio-economic contexts. Different types of advice, or alternative framing devices, may need to be adopted when communicating information to diverse cultural groups, or to older versus younger farmers. For instance, encouraging rational experimentation and innovation is likely to be more appropriate among young farmers who are more open to new ideas, whereas older farmers would perhaps respond better to advice that considers the importance of maintaining livestock as a source of wealth and prestige. In this way, religion and tradition can play a role in easing the transition to new information and practices. Paying proper respect to closely held traditional beliefs can help improve the likelihood of CSA measures being adopted, and therefore contribute to reducing the impacts of climate change and variability on the agricultural sector in southern Africa.

\section{References}

Ambani M, Percy F (2014) Facing uncertainty: the value of climate information for adaptation, risk reduction and resilience in Africa. CARE International, Nairobi. Retrieved from www. careclimatechange.org/adaptation-initiatives/alp

Angula MN, Ntombela KP, Samuels MI, Swarts M, Cupido C, Haimbili NE, Menjono-Katjizeu ME \& Hoabes M (2016) Understanding pastoralist's knowledge of climate change and variability in Arid Namibia and South Africa. In Proceedings of centenary conference of the Society of South African Geographers: 25-28 Sept 2016, Stellenbosch. Stellenbosch: Research Gate

Barnard J, Manyire H, Tambi E, Bangali S (2015) Barriers to scaling up/out climate smart agriculture and strategies to enhance adoption in Africa. Forum for Agricultural Research in Africa (FARA), Accra

Berkes F, Colding J, Folke C (2000) Rediscovery of traditional ecological knowledge as adaptive management. Ecol Appl 10(5):1251-1262

Chioreso E, Munyayi R (2015) Climate smart agriculture. Desert Research Foundation of Namibia, Windhoek. Retrieved from http://www.fao.org/docrep/018/i3325e/i3325e00.htm 
Chishakwe N, Murray L, Chambwera M (2012) Building climate change adaptation on community experiences. Pubs.Iied.Org. Retrieved from http://pubs.iied.org/pdfs/10030IIED.pdf

Conservation Agriculture Task Force for Zimababwe, C (2008) The conservation agriculture toolbox for Zimbabwe. Development. FAO. Retrieved from https://www.fsnnetwork.org/ conservation-agriculture-toolbox-zimbabwe

Corner A, Markowitz E, Pidgeon N (2014) Public engagement with climate change: the role of human values. Wiley Interdiscip Rev Clim Chang 5(3):411-422. https://doi.org/10.1002/ wcc. 269

Country Pilot Partnership for Integrated Sustainable Land Management (CPP) Programme (2012) Improved Pearl Millet Production in an arid environemnt for the improvement of livelihoods and reversal of land degradation: a case study from Omusati Region, Namibia. Ministry of Environment and Tourism; the Ministry of Agriculture, Water and Forestry; and the United Nations Development Programme, Outapi

Davies J, Ziervogel G (2017) "Learning by Doing" - lessons from the co-production of three South African municipal climate change adaptation plans. In: Fünfgeld H, Maloney S, Granberg M (eds) Local action on climate change: opportunities and constraints. Routledge, Stockholm, pp 53-71

Dieckmann U, Odendaal W, Tarr J, Schreij A (2013) Indigenous peoples and climate change in Africa: report on case studies of Namibia's Topnaar and Hai//om communities. Legal Assistance Centre, Windhoek

Dieckmann U, Thiem M, Dirkx E, Hays J (2014) "Scraping the Pot": San in Namibia two decades after independence. Legal Assistance Centre and Desert Research Foundation of Namibia, Windhoek

Doran MH, Low ARC, Kemp RL (1979) Cattle as a store of wealth in Swaziland: implications for livestock development and overgrazing in eastern and southern Africa. Am J Agric Econ 61(1):41-47 https://doi.org/10.2307/1239498

Government of the Republic of Namibia (2009) National Disaster Risk Management Policy. Office of the Prime Minister, Directorate: Disaster Risk Management. Windhoek

Government of the Republic of Namibia (1997) National Drought Policy and Strategy. National Drought Task Force, Windhoek

Hegga S, Ziervogel G, Angula M, Spear D, Nyamwanza A, Ndeunyema E, Kunamwene I, Togarep C, Morchain D (2016) Vulnerability and risk assessment in Omusati Region in Namibia: fostering people-centred adaptation to climate change. Adaptation at Scale in Semi-Arid Regions (ASSAR)

Jiri O, Mafongoya PL, Mubaya C, Mafongoya O (2016) Seasonal climate prediction and adaptation using indigenous knowledge systems in agriculture systems in Southern Africa: a review. J Agric Sci 8(5):156. https://doi.org/10.5539/jas.v8n5p156

Kassam A, Derpsch R, Friedrich T (2014) Global achievements in soil and water conservation: the case of conservation agriculture. Int Soil Water Conserv Res 2(1):5-13. https://doi.org/10.1016/ S2095-6339(15)30009-5

Kniveton D, Visman E, Tall A, Diop M, Ewbank R (2014) Dealing with uncertainty: integrating local and scientific knowledge of the climate and weather. Disasters 39(1):35-53. https://doi. org/10.1111/disa.12108

Luseno W, McPeak JG, Barrett CB, Little PD, Gebru G (2016) Assessing the value of climate forecast information for Pastoralists: evidence from southern Ethiopia and northern Kenya. Int Res Inst Clim Prediction, (February 2003). https://doi.org/10.1016/ S0305-750X(03)00113-X

MAWF (2015) Namibia agriculture policy. Government Gazette of the Republic of Namibia. Ministry of Agriculture, Water and Forestry, Windhoek

Mazzocchi F (2006) Western science and traditional knowledge. EMBO Reports (European Molecular Biology Organization) 7(5):463-466. https://doi.org/10.1038/sj.embor.7400693

Ministry of Environment and Tourism (MET) (2011) National Climate Change Policy for Namibia. United Nations Development Programme, Namibia 
Ministry of Environment and Tourism (2015) Republic of Namibia Country climate smart agriculture programme 2015-2030. Ministry of Environment and Tourism and Ministry of Agriculture, Water and Forestry, Windhoek

Mogotsi K, Moroka AB, Sitang O, Chibua R (2011) Seasonal precipitation forecasts: agroecological knowledge among rural Kalahari communities. Afr J Agric Res 6(4):916-922. https://doi.org/10.5897/AJAR10.756

Newsham AJ, Thomas DSG (2011) Knowing, farming and climate change adaptation in North-Central Namibia. Glob Environ Chang 21(2):761-770. https://doi.org/10.1016/j. gloenvcha.2010.12.003

Reid H, Huq S, Murray L (2010) Community champions: adapting to climate challenges. International Institute for Environment and Development, London

Roberts D (2008) Thinking globally, acting locally - institutionalizing climate change at the local government level in Durban, South Africa. Environ Urban 20(2):521-537. https://doi. org/10.1177/0956247808096126

Sachdeva S (2016) Religious identity, beliefs, and views about climate change. Oxford Res Encycl Clim Sci (1). https://doi.org/10.1093/acrefore/9780190228620.013.335

Schwartz SH (1992) Universals in the content and structure of values: theoretical advances and empirical tests in 20 countries. Adv Exp Soc Psychol 25(C):1-65. https://doi.org/10.1016/ S0065-2601(08)60281-6

Selato J (2017) Credibility and scale as barriers to the uptake and use of seasonal climate forecasts in Bobirwa Sub-District, Botswana. Department of Environmental and Geographical Sciences University of Cape Town 1, Cape Town

Sibanda LM, Mwamakamba SN, Mentz M, Mthunzi T (eds) (2017) Policies and practices for climate-smart agriculture in Sub-Saharan Africa: a comparative assessment of challenges and opportunities across 15 countries. Food, Agriculture and Natural Resource Policy Analysis Network (FANRPAN), Pretoria

Singh C, Daron J, Bazaz A, Ziervogel G, Spear D, Krishnaswamy J, Zaroug M, Kituyi E (2017) The utility of weather and climate information for adaptation decision-making: current uses and future prospects in Africa and India. Clim Dev:1-17. https://doi.org/10.1080/17565529. 2017.1318744

Spear D, Baudoin MA, Hegga S, Zaroug M, Okeyo AE Haimbili E (2015) Vulnerability and adaptation to climate change in the semi-arid Regions of Southern Africa, 111

Speranza CI (2010) Drought coping and adaptation strategies: understanding adaptations to climate change in agro-pastoral livestock production in makueni district, Kenya. Eur J Dev Res 22(5):623-642. https://doi.org/10.1057/ejdr.2010.39

Stroebel A, Swanepoel FJC, Nthakheni ND, Nesamvuni AE, Taylor G (2008) Benefits obtained from cattle by smallholder farmers: a case study of Limpopo Province, South Africa. Aust J Exp Agric 48(7):825-828. https://doi.org/10.1071/EA08058

Thomalla F, Smith R, Schipper ELF (2015) Cultural aspects of risk to environmental changes and hazards a review of perspectives. In: Disaster's impact on livelihood and cultural survival, (1), 3-18. https://doi.org/10.1201/b18233-3

Togarepi C, Thomas B, Kankono M (2016) Cattle marketing constraints and opportunities in north-central communal areas of Namibia, Ohangwena region. Livest Res Rural Dev 28:7

Verlinden A, Dayot B (2005) A comparison between indigenous environmental knowledge and a conventional vegetation analysis in north central Namibia. J Arid Environ 62(1):143-175. https://doi.org/10.1016/j.jaridenv.2004.11.004

Williams T, Mul M, Cofie O, Kinyangi J (2015) Climate smart agriculture in the African context. Cgspace.Cgiar.Org (October). Retrieved from https://cgspace.cgiar.org/bitstream/handle/10568/68944/Climate_Smart_Agriculture_in_the_African_Context[1].pdf?sequence=1

Ziervogel G (2016) What Africa's drought responses teaches us about climate change hotspots. Water Wheel 15(5):31-33 
Ziervogel G, Calder R (2003) Climate variability and rural livelihoods: assessing the impact of seasonal climate forecasts in Lesotho. Society:403-417. https://doi. org/10.1111/j.0004-0894.2003.00190.x

Ziervogel G, Opere A (2010) Integrating meteorological and indigenous knowledge-based seasonal climate forecasts for the agricultural sector. International Development Research Centre, Ottawa, Canada. Climate Change Adaptation in Africa Learning Paper Series. Retrieved from http://web.idrc.ca/uploads/user-S/12882908321CCAA_seasonal_forecasting.pdf

Open Access This chapter is licensed under the terms of the Creative Commons Attribution 4.0 International License (http://creativecommons.org/licenses/by/4.0/), which permits use, sharing, adaptation, distribution and reproduction in any medium or format, as long as you give appropriate credit to the original author(s) and the source, provide a link to the Creative Commons license and indicate if changes were made.

The images or other third party material in this chapter are included in the chapter's Creative Commons license, unless indicated otherwise in a credit line to the material. If material is not included in the chapter's Creative Commons license and your intended use is not permitted by statutory regulation or exceeds the permitted use, you will need to obtain permission directly from the copyright holder.

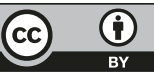

